\title{
A phenomenological model to evaluate the performances of electrodialysis for the desalination of saline water containing organic solutes
}

\author{
Le $\operatorname{Han}^{1}$, Sylvain Galier, Hélène Roux-de Balmann* \\ Laboratoire de Génie Chimique, Université de Toulouse, CNRS, INPT, UPS, Toulouse, France
}

Keywords:

Electrodialysis

Model

Desalination

Mass transfer

Organic solute

\begin{abstract}
A B S T R A C T
Electrodialysis is promising to treat saline solutions containing organic solutes. However, there is still a need for a model to describe the desalination performances according to the process parameters. In this work a phenomenological model is proposed based on the analysis of the different contributions to the mass transfer of salt, water, and organic compounds. Once the characteristic parameters are determined experimentally, it is possible to predict the salt and organic concentrations in both compartments according to the operating conditions. The methodology is illustrated for the evaluation of electrodialysis performances considering a case study, and the effect of the current and solution compositions are discussed. To remove a fixed salt quantity, a lower current gives a higher organic solute transfer due to a higher time dependent solute diffusion, the additional transfer, fixed by the quantity of charge, remaining constant. Regarding the influence of the inorganic salts, higher transfer of organics, like glucose, acetic acid or acetate, are observed with sulfate compared to chloride, while a contrary behavior is obtained with phenol. This model also permits to discuss the influence of possible pretreatments to change the $\mathrm{pH}$ or the salt composition in order to improve the electrodialysis performances.
\end{abstract}

\section{Introduction}

Aqueous waste streams of increasing quantities are often complex, containing salt and organic matter (OM) [1]. Membrane processes like nanofiltration (NF) or electrodialysis (ED) are very promising for the separation of the organic compounds and the salt, leading to a feasible treatment, reuse and/or valorization of these fractions. ED can be better option due to process availability in varying salinity range and flexibility for process control e.g. on current [2,3]. In addition, successful applications of ED for desalting complex saline solutions in varying fields of biotechnological, chemical industries and water treatment systems are reported, with solution containing both organic solute and salt [4-7]. In each case, two different streams are produced, as shown in Fig. 1.

Considering further integration of the produced streams, ED desalination can have many different objectives. Concerning the organic content, the solute decomposition or recovery could be the objective depending whether it is a pollutant or valuable fraction. Meanwhile, concerning the salt extracted in the concentrate, further utilization such as production of raw materials or exploitation salinity gradient energy is of great interest [8]. Nevertheless, it is noteworthy that desalination and organic solute transfer occur simultaneously. The process control regarding the solution impurity in the diluate and concentrate should be given to great attention, as it may limit the integrated process followed.

In fact, previous ED studies mainly focus on partial factors like solute concentration and nature, membrane type selection, operating current, $\mathrm{pH}$ and system running mode etc. [7,9-13], while a systematic investigation concerning ED performance for the separation of the organic solute/salt is still lacked. Moreover, in such cases, the membranes, the salt and organic solute together build a complex system, making process performance hard to predict [14]. For instance, the salt transfer (to be maximized) and the simultaneous organic solute transfer (to be minimized) are reported to be highly linked due to the water electroosmosis and the applied current in ED [14,15]. Furthermore, modification on both the ion-exchange membrane (IEM) structural [16] and the solute hydration [17] by salt has been reported, possibly resulting to unexpected poor performance of ED. Thus, considering a complex interaction among salt-solute-membrane involved, a theoretic model in order to better predict/understand ED performance is urgently necessary. However, few studies focus on the predicted model for ED process [6], with only limited solution investigated such as in agroprocessing field $[18,19]$. Furthermore, the model based on NernstPlanck equation integrating many parameters is often hard to use in

\footnotetext{
* Corresponding author.

E-mail address: roux@chimie.ups-tlse.fr (H.R.-d. Balmann).

${ }^{1}$ Present address: School of Chemical and Biomedical Engineering, Nanyang Technological University, 637459, Singapore.
} 


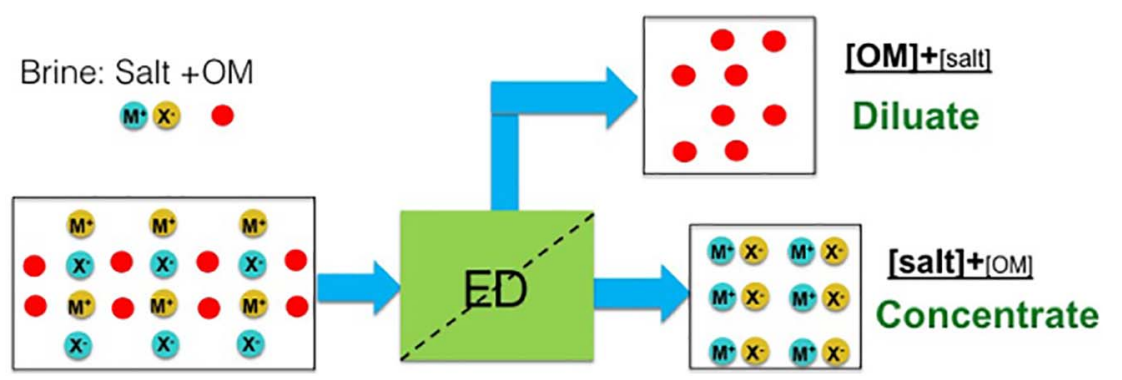

real practice of different aspects [20].

The aim of this study is to propose a simple, phenomenological model to evaluate the ED performance desalting various saline brines containing organic solute. Synthetic saline solutions consisting of different salt ( $\mathrm{NaCl}, \mathrm{MgCl}_{2}, \mathrm{Na}_{2} \mathrm{SO}_{4}$, respectively) mixed with varying organic compounds (namely acetic acid, phenol and glucose as neutral compounds and acetate as charged one) are used. Based on the mass transfer investigation, characteristic parameters of the proposed model are experimentally obtained. Then, according to the model, the ED process performance is discussed concerning the influence of the current and solution composition (the salt and organic solute), on the variation of solute concentration for both two streams, i.e., diluate and concentrate.

\section{Phenomenological modelling based on mass transfer}

A phenomenological model in the ED process is depicted according to the transfer of inorganic salt, water and organic compound. Then, the variation of the solute concentration in each compartment can be predicted with the proposed model, enabling to further evaluate the process performance.

\subsection{Inorganic salt and water transfer}

The salt flux in ED, $j_{s}\left(\mathrm{eq} \cdot \mathrm{m}^{-2} \cdot \mathrm{s}^{-1}\right)$, is reported to be dominated by migration due to the electrical potential gradient, $j^{m i g}$, which is proportional to the current $[2,6,19]$. The salt flux density is expressed as in Eq. (1), introducing the current coefficient $\alpha\left(\mathrm{eq} \cdot \mathrm{m}^{-2} \cdot \mathrm{s}^{-1} \cdot \mathrm{A}^{-1}\right)$ :

$j_{s} \approx j^{m i g}=\alpha I$

In the same manner, it is reported that the water transfer, $j_{w}$ $\left(\mathrm{m}^{3} \cdot \mathrm{m}^{-2} \cdot \mathrm{s}^{-1}\right)$, is dominated by the electroosmotic flux $\left(j^{e o}\right)$, i.e. the water transfer owing to the migration of ion species, corresponding to the ion hydration $[2,6,21,22]$. Due to its relation with the salt transfer, electroosmosis $j^{e o}$ varies linearly with the current. Then, the water flux density is given by Eq. (2), by introducing an electroosmotic coefficient, $\beta\left(\mathrm{m}^{3} \cdot \mathrm{m}^{-2} \cdot \mathrm{s}^{-1} \cdot \mathrm{A}^{-1}\right)$ :

$j_{w} \approx j^{e o}=\beta I$

\subsection{Organic solute transfer}

It is documented that the mass transfer of the organic compound can be owing to the diffusion driven by the concentration gradient [23]. But an additional contribution was demonstrated to be also involved (convection for neutral solute and migration for charged solute) and that it is not negligible compared to diffusion, which is further discussed later $[6,12,24-26]$. The flux of organic solute, $j_{O M}$, consisting of the diffusion flux, $j^{\text {diff }}$, and the additional flux, $j^{\text {additional }}$ is given by Eq. (3):

$j_{O M}=j^{\text {diff }}+j^{\text {additional }}$

Concerning the diffusion transfer, it can be further expressed as: $j^{\text {diff }}=P_{O M} \Delta C_{O M}$

where $\Delta C_{O M}$ is the concentration gradient $\left(\Delta C_{O M}=C_{O M, D}{ }^{0}-C_{O M, C}{ }^{0}\right)$ and $P_{O M}\left(\mathrm{~m} \cdot \mathrm{s}^{-1}\right)$ is the solute permeability. $\Delta C_{O M}$ is assumed to be constant in this study, with the value equal to $C_{O M, D}{ }^{0}$, the initial organic solute concentration in diluate (feed). Indeed, comparing with the initial amount added in the diluate, this amount of transferred organic compound is negligible which will be further discussed in Section 4.2.

Concerning the additional transfer, it corresponds to two cases, considering different solute charge nature. For a neutral organic solute, the additional transfer was reported to be convection due to electroosmosis which is proportional to the current $[14,15]$. A charged organic solute is supposed to migrate under current, same to inorganic charged species above mentioned. Thus, the migration of the charged solute is also proportional to the current, referred to Eq. (1).

Therefore, the additional transfer of organic solute, whatever charge nature, can be expressed as follows:

$j^{\text {additional }}=\gamma I$

introducing $\gamma\left(\mathrm{mol} \cdot \mathrm{m}^{-2} \cdot \mathrm{s}^{-1} \cdot \mathrm{A}^{-1}\right)$ as the additional transfer characteristic coefficient.

The total flux of solute transfer, shown as Eq. (3) can be rewritten as Eq. (6):

$j_{O M}=j^{\text {diff }}+j^{\text {additional }}=P_{O M} C_{O M, D}^{0}+\gamma I$

consisting of diffusion, which is characterized by coefficient $P_{O M}$ $\left(\mathrm{m} \cdot \mathrm{s}^{-1}\right)$, and an additional transfer, characterized by $\gamma$ $\left(\mathrm{mol} \cdot \mathrm{m}^{-2} \cdot \mathrm{s}^{-1} \cdot \mathrm{A}^{-1}\right)$.

\subsection{Solute concentration variation}

Knowing the transfer of solute and water across the ion-exchange membrane, the quantity of the solute and water in real time in the two compartments can be calculated, based on mass balance analysis for an ED experiment run in a batch mode. Then, the concentration of salt $\left(C_{S}\right.$, eq. $\left.\mathrm{m}^{-3}\right)$ and concentration of organic solute $\left(C_{O M}, \mathrm{~mol} \cdot \mathrm{m}^{-3}\right)$ resepctively are given by:

for the concentrate compartment:

$C_{s}^{C}=\frac{C_{s, \mathrm{C}}^{0} V_{C}^{0}+\alpha I S_{m} t}{V_{C}^{0}+2 \beta I S_{m} t}$

$C_{O M}^{C}=\frac{\left(P_{O M} C_{O M, D}^{0}+\gamma I\right) 2 S_{m} t}{V_{C}^{0}+2 \beta I S_{m} t}$

then based on the mass balance, for the diluate compartment:

$C_{s}^{D}=\frac{C_{s, \mathrm{D}}^{0} V_{D}^{0}-\alpha I S_{m} t}{V_{D}^{0}-2 \beta I S_{m} t}$

$C_{O M}^{D}=\frac{C_{O M}^{0} V_{D}^{0}-\left(P_{O M} C_{O M, D}^{0}+\gamma I\right) 2 S_{m} t}{V_{D}^{0}-2 \beta I S_{m} t}$

The numerators and denominators describe the solute quantity and solvent quantity at each time $t$, respectively. The four characteristic parameters for solute and solvent transfer $\left(\alpha, \beta, P_{O M}\right.$ and $\left.\gamma\right)$ are obtained 
experimentally. $\alpha$ and $\beta$ can be determined from the variations of flux density versus current for salt and water, respectively; $P_{O M}$, i.e., the solute permeability, can be deduced according to diffusion flux, while $\gamma$, i.e. the additional transfer coefficient can be determined from the variations of organic solute flux density versus current.

Other parameters in Eqs. (7)-(10) are from solution characteristics like initial solute concentration $\left(C_{s}^{0}, C_{O M}{ }^{0}\right)$ and solution volume $\left(V_{C}{ }^{0}, V_{D}{ }^{0}\right)$, and from the electrodialysis apparatus such as membrane surface for one type $\left(\mathrm{S}_{\mathrm{m}}\right)$ or operation parameters like current (I) and time $(t)$. It is noteworthy that inorganic salt transfer concerns effective membrane surface as $S_{m}$, while water and organic solute transfer concerns membrane surface as $2 \mathrm{~S}_{\mathrm{m}}$ (the surface referring to the transfer of water and organics is the total membrane area, including both AEM and CEM, i.e. $2 S_{m}, S_{m}$ referring to the surface of one type of membrane only).

The variation of solute concentration is then possible to be predicted in real time. The unit of the solute concentration is changeable depending on the investigated condition, e.g. for process point of view, a change of $C_{O M}$ unit from mole to ppm by multiplying solute $\mathrm{M}_{\mathrm{w}}$.

\section{Materials and methods}

\subsection{Salt and organic solutes}

Three inorganic salts were selected: $\mathrm{NaCl}, \mathrm{Na}_{2} \mathrm{SO}_{4}, \mathrm{MgCl}_{2}$ containing ions of various hydrations. The sequence of ion hydration for anion and cation respectively is reported as [22]:

Anions: $\mathrm{Cl}^{-}<\mathrm{SO}_{4}{ }^{2-}$ cations: $\mathrm{Na}^{+}<\mathrm{Mg}^{2+}$

Four organic solutes of varying characteristics used in this study are reported in Table 1, including three neutral and one charged solutes. They were chosen since they typically represent the ones found in different saline fluids, characterized with varying molecular weights $\left(\mathrm{M}_{\mathrm{w}}\right)$, hydrophobicity and charge.

Notably, Table 1 reports the $\mathrm{pH}$ value of each synthetic solution when organic compound was dissolved, without adjustment, regardless of the presence of salt. Particularly, the $\mathrm{pH}$ value of solution containing acetic acid is ca. 3.0. This indicates that $<5 \%$ of the acetic acid is dissociated (i.e. as acetate), considering the pKa value. In the pH conditions investigated here, one can further consider that acetic acid, phenol and glucose are neutral. Phenol is the most hydrophobic solute (indicated by the highest value of $\log$ P), with acetic acid second and glucose followed (lowest $\log$ P). This sequence can be mainly attributed to the different solute functional groups of benzene carboxyl and hydroxyl (Table 1). Acetate is negatively charged, with its $\mathrm{M}_{\mathrm{w}}$ close to acetic acid.

The concentration for organic solute was $0.1 \mathrm{~mol} \cdot \mathrm{L}^{-1}$, and the concentration of inorganic salt (compared to sodium acetate, i.e. an organic salt) was $0.8 \mathrm{eq} \cdot \mathrm{L}^{-1}$.

\subsection{Membrane and electrodialysis set-up}

The ED stack used in this study (EUR 2B-10, Eurodia, France) consisting of 10 cells of anion- exchange membrane (AEM) and cationexchange membrane (CEM), i.e., Neosepta AMX/CMX, from Tokuyama

Table 1

Characteristics of the four organic solutes used in this study.

\begin{tabular}{llllll}
\hline \multicolumn{2}{l}{ Chemical name and formula } & $\mathrm{M}_{\mathrm{w}}\left(\mathrm{g} \cdot \mathrm{mol}^{-1}\right)$ & $\log \mathrm{P}^{\mathrm{a}}$ & $\mathrm{pKa}$ & $\mathrm{pH}$ \\
\hline Glucose & $\mathrm{C}_{6} \mathrm{H}_{12} \mathrm{O}_{6}$ & 180.16 & -2.93 & 12.28 & $6.0 \pm 0.5$ \\
Phenol & $\mathrm{C}_{6} \mathrm{H}_{5} \mathrm{OH}$ & 94.11 & 1.48 & 9.99 & $5.4 \pm 0.3$ \\
Acetic acid & $\mathrm{C}_{2} \mathrm{H}_{4} \mathrm{O}_{2}$ & 60.05 & -0.32 & 4.76 & $3.0 \pm 0.2$ \\
Acetate & $\mathrm{C}_{2} \mathrm{H}_{3} \mathrm{O}_{2}{ }^{-}$ & 59.04 & - & 4.76 & $6.7 \pm 0.3$ \\
\hline
\end{tabular}

${ }^{a}$ Solute hydrophobicity ( $\mathrm{P}$, partition coefficient between solvents of octanol and water) [27].
Corp, Japan $[6,19,22]$. The effective membrane surface for each type (AEM or CEM) is $0.02 \mathrm{~m}^{2}$ per cell, giving a total area for each type of membrane $\left(\mathrm{S}_{\mathrm{m}}\right) 0.2 \mathrm{~m}^{2}$.

The electrodialysis set-up has three loops, for diluate and concentrate as well as electrode solution respectively. Batch mode operation was used to carry out the experiments, with constant flowrates of $180 \mathrm{~L}^{-1}{ }^{-1}$ for concentrate and diluate (corresponding to a linear flow velocity of $10 \mathrm{~cm} \cdot \mathrm{s}^{-1}$ ), $360 \mathrm{~L} \cdot \mathrm{h}^{-1}$ for electrode solution. Constant operation temperature of $25 \pm 1{ }^{\circ} \mathrm{C}$ was fixed by a circulating thermostatic bath for each experiment [22].

The electrode solution was $10 \mathrm{~g} \cdot \mathrm{L}^{-1} \mathrm{Na}_{2} \mathrm{SO}_{4}$ of $3 \mathrm{~L} .2 \mathrm{~L}$ of the salt solution with the organic solute was fed into diluate compartment, while another $2 \mathrm{~L}$ of the same salt solution but without organic solute was fed into the concentrate compartment.

\subsection{Protocol}

For each experiment, the ion-exchange membranes were soaked firstly by saline water with same composition as in ED experiments, following a previously stated procedure $[14,15,22,28]$. The IEMs were consequently regarded in their counter-ion form, in order to highlight the impact of salt on membrane structure [28].

Experiments were then performed without current $(I=0)$, corresponding to a diffusion system, and with current $(I \neq 0)$. Without current, owing to the concentration difference, the solute diffusion from diluate to concentrate was noticed. Under normal ED conditions, four currents $(2,3,4,6 \mathrm{~A})$ corresponding to a current density ranging $0-300 \mathrm{~A} \cdot \mathrm{m}^{-2}$ were used. All the ED experiments were stopped before the final conductivity of diluate reached $5 \mathrm{mS} \cdot \mathrm{cm}^{-1}$ to avoid exceeding the limiting current. As a consequence, experiment durations varied from case to case. The fluxes for solvent and solute (inorganic salt and organic compound) were determined according to the solution volume and the transferred solute quantity variation with time, respectively.

\subsection{Analytical methods}

Solution $\mathrm{pH}$, conductivities, temperature for both diluate and concentrate as well as the system voltage were monitored in real time.

The ionic species concentrations were measured by ion chromatography (IEC, Dionex, France) [22]. The concentrations of organic solutes except phenol were determined by HPLC (Jasco, France) [14], while UV spectroscopy determines the concentration of phenol [6]. Samples dilution was carried out before each analysis and more details are referred to $[14,22]$.

The maximum deviation of mass balance is no $>2 \%$ for water, $5 \%$ for ions, $10 \%$ for organic solute, respectively.

\section{Results and discussions}

Firstly, the transfer for inorganic salt $(\alpha)$ and water $(\beta)$ are investigated, and then the transfer of organic solute across the membranes is studied without current $\left(P_{O M}\right)$ and with current $(\gamma)$, respectively. After determining these four parameters, the model is used to evaluate the ED performances with a regard to the effect of the current, the solute and the salt.

\subsection{Inorganic salt and water transfer}

The inorganic salt and water flux is deduced from the linear variation of the transferred quantity versus time $\left(\mathrm{R}^{2}>99 \%\right)$ respectively, according to the experiment results for each current (not shown here), in agreement with previous results [14,22]. Fig. 2 depicts the variations of these fluxes versus current.

Fluxes for the inorganic salt and water vary linearly with the current $\left(\mathrm{R}^{2}>99 \%\right)$, respectively. This finding confirms that migration dominates the salt transfer and electroosmosis dominates the water transfer 


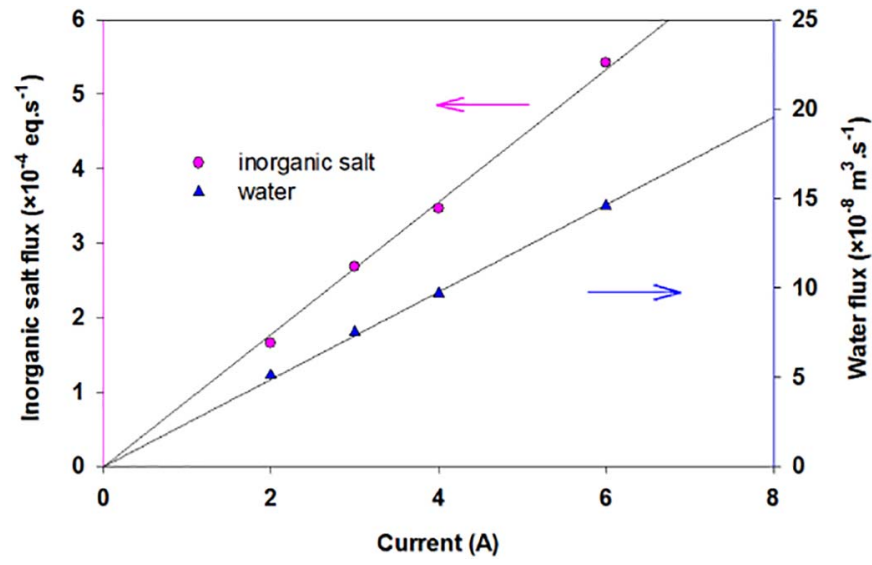

Fig. 2. Flux variation of the inorganic salt and water versus current; system consisting of $\mathrm{NaCl}$ and acetate, [salt] $=0.8 \mathrm{eq} \cdot \mathrm{L}^{-1}$, [organic solute] $=0.1 \mathrm{~mol} \cdot \mathrm{L}^{-1}$.

under current, as stated in Eqs. (1) and (2) respectively. Such results are observed under any investigated condition.

The coefficients $\alpha$ and $\beta$ are determined by Eqs. (1) and (2). For different solutions investigated here, Table 2 reports all the values of current coefficients $\alpha$, showing one corresponding $\alpha$ value for each neutral solute, two corresponding values for the charged solute (with the total $\alpha$ value considering the transfer of both the inorganic salt and sodium acetate), in parallel with the case without any organic solute.

Values excluding the inorganic $\alpha$ for sodium acetate are firstly dicussed. Results for the three neutral solutes are already discussed in [14], showing the current coefficient $\alpha$ is mainly fixed by the current, without significant variations with the composition of solution. The same finding is observed for the value of the total $\alpha$ for acetate, as well as in the case without any organic solute.

For acetate, as expected, lower value for the inorganic salt, compared with the total one is observed for each salt composition. Concerning different salt compositions, the values for the inorganic salt varies, showing the transfer of $\mathrm{SO}_{4}{ }^{2-}$ for $\mathrm{Na}_{2} \mathrm{SO}_{4}$ system (4.0) is slightly lower than those of $\mathrm{Cl}^{-}$for $\mathrm{NaCl}$ and $\mathrm{MgCl}_{2}$ systems (ca. 4.5). Considering comparable values of total $\alpha$ for different systems, this indicates a possible different transfer of acetate with the presence of different inorganic anions, which is further disscussed in Section 4.2.

Regarding the water transfer, the determined electroosmotic coefficients are reported in Table 3 for the different systems investigated, in parallel with the case without any organic solute.

For a fixed solute, it is observed that $\beta$ varies with the composition of salt (maximum variation ca. $30 \%$ ). For each solute, one can find the same trend for $\beta$ as $\mathrm{MgCl}_{2}>\mathrm{NaCl}>\mathrm{Na}_{2} \mathrm{SO}_{4}$. Then, for varying organic compounds, Table 3 shows that the values of glucose and acetic acid as well as acetate are close, and very comparable to those obtained in case without any organic solute, slightly higher than the values obtained with phenol (difference below 12\%). This agrees with the previous report on neutral organic solute [14].

Since the water transfer consists of a total contribution of each ion's hydration [22], the reported $\beta$ is a global parameter. Particularly in the case of acetate, the value of $\beta$ consists of both the contribution of the
Table 3

Electroosmotic coefficient $\left(\beta, \mathrm{m}^{3} \cdot \mathrm{m}^{-2} \cdot \mathrm{s}^{-1} \cdot \mathrm{A}^{-1}\right)$ for varying systems according to Eq. (2); [inorganic salt] $=0.8 \mathrm{eq} \cdot \mathrm{L}^{-1}$, [organic solute] $=0.1 \mathrm{~mol} \cdot \mathrm{L}^{-1}$.

\begin{tabular}{llllll}
$\beta \times 10^{-8} \mathrm{~m}^{3} \cdot \mathrm{m}^{-2} \cdot \mathrm{s}^{-1} \cdot \mathrm{A}^{-1}$ & Glucose & Phenol & Acetic acid & Acetate $\begin{array}{l}\text { No } \\
\text { organic } \\
\text { solute } \\
{[22]}\end{array}$ \\
& & & & & \\
\hline $\mathrm{MgCl}_{2}$ & 6.6 & 6.1 & 7.0 & 6.6 & 6.8 \\
$\mathrm{NaCl}$ & 5.9 & 5.5 & 6.3 & 6.1 & 5.8 \\
$\mathrm{Na}_{2} \mathrm{SO}_{4}$ & 5.6 & 5.1 & 5.9 & 6.0 & 5.6
\end{tabular}

inorganic salt and sodium acetate, whereas for the other cases only the inorganic salt's contribution is involved. Nevertheless, no significant variation of $\beta$ is observed comparing the case of acetate with the others. This is because water transfer due to acetate is negligible, due to a very low concentration comparing to the inorganic salts (1:8).

\subsection{Organic solute transfer}

Transfer of organic solute without current (in diffusion system) and then with current are studied. In each system, considering the solutemembrane interaction, the results for three neutral solutes are firstly discussed together. Then for the charged solute, i.e. acetate, its transfer is discussed in comparison with acetic acid.

\subsubsection{Transfer of organic solute without current}

Diffusion flux of organic solute is deduced from the linear variation for transferred solute quantity with time $\left(\mathrm{R}^{2}>98 \%\right)$ observed in the experiment (results not shown here), agreeing with literatures $[14,15]$. The obtained solute permeability according to Eq. (4), characterizing the diffusion transfer for varying systems are shown in Table 4.

The results for the neutral solutes highlight the steric effect governing the transfer of neutral solute transfer across the IEM and influence of salt (ion hydration) referred as membrane swelling effect, which are already discussed in our previous work [14].

The transfer of acetate is compared with that of acetic acid, of similar $\mathrm{M}_{\mathrm{w}}$ but different charge nature to acetate. Acetate permeability is always lower than that of acetic acid in each case, by a factor of ca. 2 . Regarding the effect of salt, different behavior of acetate transfer $\left(\mathrm{NaCl}<\mathrm{MgCl}_{2} \approx \mathrm{Na}_{2} \mathrm{SO}_{4}\right)$ is also observed, compared to the fixed sequence found for the neutral solute $\left(\mathrm{NaCl}>\mathrm{MgCl}_{2}>\mathrm{Na}_{2} \mathrm{SO}_{4}\right)$. This can be attributed to the additional electrostatic effects for acetate which influences its transfer, compared to the steric effect for acetic acid. The transfer mechanism is out of the scope of this work.

\subsubsection{Transfer of organic solute with current}

Under each current, the flux of organic compound is deduced from a linear variation of solute transfer versus time $\left(\mathrm{R}^{2}>98 \%\right)$ according to the experiment results for each current (not shown here), in line with literatures [14,15]. Fig. 3 depicts variations of organic solute flux with current including diffusion ( $\mathrm{I}=0$ ), using systems containing $\mathrm{NaCl}$ as an example.

Regarding the neutral solutes, the sequence for the flux density of organic compound under each current is reported as: glucose <

Table 2

Current coefficient $\left(\alpha, \mathrm{eq} \cdot \mathrm{m}^{-2} \cdot \mathrm{s}^{-1} \cdot \mathrm{A}^{-1}\right)$ for varying systems according to Eq. (1); [inorganic salt] $=0.8$ eq $\cdot \mathrm{L}^{-1}$, [organic solute] $=0.1 \mathrm{~mol} \cdot \mathrm{L}^{-1}$.

\begin{tabular}{|c|c|c|c|c|c|c|}
\hline \multirow[t]{2}{*}{$\alpha \times 10^{-4} \mathrm{eq} \cdot \mathrm{m}^{-2} \cdot \mathrm{s}^{-1} \cdot \mathrm{A}^{-1}$} & \multirow{2}{*}{$\frac{\text { Glucose }}{\text { Inorganic }}$} & \multirow{2}{*}{$\begin{array}{l}\text { Phenol } \\
\text { Inorganic }\end{array}$} & \multirow{2}{*}{$\begin{array}{l}\text { Acetic acid } \\
\text { Inorganic }\end{array}$} & \multicolumn{2}{|c|}{ Sodium acetate } & \multirow{2}{*}{$\begin{array}{l}\text { No organic solute [22] } \\
\text { Inorganic }\end{array}$} \\
\hline & & & & Inorganic & Total* & \\
\hline $\mathrm{MgCl}_{2}$ & 5.1 & 4.5 & 4.7 & 4.6 & 4.7 & 4.9 \\
\hline $\mathrm{NaCl}$ & 5.0 & 4.5 & 5.1 & 4.4 & 4.9 & 4.6 \\
\hline $\mathrm{Na}_{2} \mathrm{SO}_{4}$ & 4.9 & 4.4 & 4.8 & 4.0 & 4.7 & 4.8 \\
\hline
\end{tabular}

Total*: this value includes contribution of both the inorganic and acetate 
Table 4

Organic solute permeability in different diffusion systems according to Eq. (4); [inorganic salt $]=0.8 \mathrm{eq} \cdot \mathrm{L}^{-1}$, [organic solute $]=0.1 \mathrm{~mol} \cdot \mathrm{L}^{-1}$.

\begin{tabular}{lllll}
\hline $\mathrm{P} \times 10^{-8} \mathrm{~m} \cdot \mathrm{s}^{-1}$ & Glucose & Phenol & Acetic acid & Acetate \\
\hline $\mathrm{NaCl}$ & 1.2 & 7.5 & 8.1 & 4.2 \\
$\mathrm{MgCl}_{2}$ & 1.1 & 6.8 & 7.4 & 5.7 \\
$\mathrm{Na}_{2} \mathrm{SO}_{4}$ & 1.0 & 4.5 & 7.0 & 5.4 \\
\hline
\end{tabular}

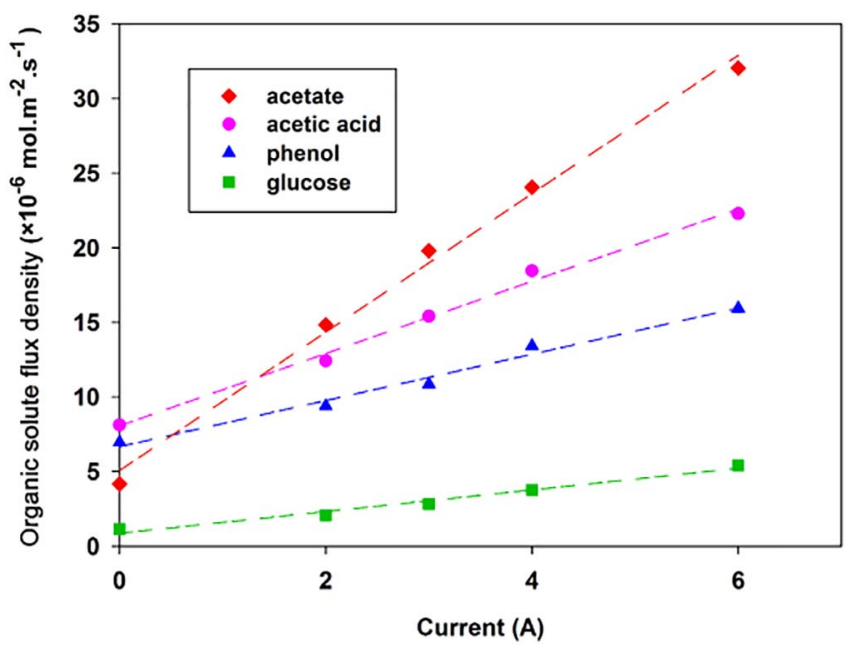

Fig. 3. Variation of the organic solutes flux density versus current for varying $\mathrm{NaCl}$ / organic solute systems; $[\mathrm{NaCl}]=0.8 \mathrm{eq} \cdot \mathrm{L}^{-1}$, [organic solute $]=0.1 \mathrm{~mol} \cdot \mathrm{L}^{-1}$.

phenol $<$ acetic acid, in agreement with that the steric effect governing the neutral compound transfer across IEM [14]. This result for the charged solute shows that acetate is more sensitive to the current. Comparing with acetic acid, acetate has a lower diffusion flux, while higher flux under the investigated current since $2 \mathrm{~A}$. The above sequence for $\mathrm{NaCl}$ system is found in other cases.

Fig. 3 shows that the flux density linearly increases with the current, beginning with the value for diffusion $(I=0)$. These findings agree with Eq. (3), clearly showing two contributions i.e. diffusion and additional one for the solute transfer, with the latter proportional to the current $\left(\mathrm{R}^{2}>98 \%\right)$, which is found in each system investigated here.

As aforementioned, the additional transfer for neutral solute is convection due to the electroosmosis flux and for charged solute it is migration. Then, in each case, the coefficient $\gamma$ determined as the slope in Fig. 3 (the variation of the flux density versus current), characterizes this additional transfer. Table 5 reports all the $\gamma$ values from varying systems investigated.

One can find that $\gamma$ values vary with organic solute. Given a fixed salt, the following order of sequence as acetate $>$ acetic acid $>$ phenol $>$ glucose is always found. This result suggests migration (acetate) can be more important than convection (neutral solute), in agreement with the aforementioned solute transfer.

On the other hand, the influence of salt composition is discussed, starting with the neutral solute [14]. Except the surprisingly low $\gamma$ value for phenol - $\mathrm{Na}_{2} \mathrm{SO}_{4}$ system, which is probably due to specific interaction, other results are in line with the solute dehydration effect, where a

Table 5

Additional transfer coefficients $\gamma$ for varying organic solutes according to Eq. (6); [inorganic salt] $=0.8 \mathrm{eq} \cdot \mathrm{L}^{-1}$, [organic solute] $=0.1 \mathrm{~mol} \cdot \mathrm{L}^{-1}$.

\begin{tabular}{lllll}
\hline$\gamma \times 10^{-7} \mathrm{~mol} \cdot \mathrm{m}^{-2} \cdot \mathrm{s}^{-1} \cdot \mathrm{A}^{-1}$ & Glucose & Phenol & Acetic acid & Acetate \\
\hline $\mathrm{NaCl}$ & 7.3 & 15.5 & 24.3 & 46.4 \\
$\mathrm{MgCl}_{2}$ & 7.6 & 17.9 & 25.1 & 41.8 \\
$\mathrm{Na}_{2} \mathrm{SO}_{4}$ & 8.4 & 8.8 & 30.3 & 200.0 \\
\hline
\end{tabular}

higher convection flux was reported with an increasing ion hydration $[14,15]$.

For acetate, regarding the nature of salt, similar values with $\mathrm{NaCl}$ and $\mathrm{MgCl}_{2}$ are observed, higher than those for acetic acid by a factor of ca. 2 . However, the acetate $-\mathrm{Na}_{2} \mathrm{SO}_{4}$ system gives the highest $\gamma$ value. In fact, for both acetic acid and acetate, an identical trend as $\mathrm{Cl}^{-}<\mathrm{SO}_{4}^{2-}$ is shown, with the trend more pronounced on acetate. For acetic acid, this trend is mainly attributed to the fact that $\mathrm{SO}_{4}{ }^{2-}$ has a stronger solute dehydration than $\mathrm{Cl}^{-}$, which can facilitate the solute transfer [17]. For acetate, this result suggests an additional effect arising from the acetate migration with presence of inorganic anion, i.e. membrane selectivity, which deserves future investigation.

\subsection{ED desalination process performance}

Once obtaining the characteristic parameters of mass transfer, one can evaluate ED process performance according to the proposed phenomenological model. As aforementioned, there are many different objectives for ED desalination, regarding varying water characteristic in different field. Then a case study in waste water treatment field, i.e. to biologically oxidize the pollutant organic content, was selected in order to illustrate the factors influencing the ED performance.

It is reported that higher salinity than a critical salt concentration inhibits the activity of the microbial, resulting into a limited biodegradation of the target organic compounds [29,30]. Hence, ED desalination as pretreatment before biological process is to decrease salt concentration until its critical concentration, e.g. $0.3 \mathrm{eq} \cdot \mathrm{L}^{-1}$ for sodium chloride (ca.18 $\mathrm{g} \cdot \mathrm{L}^{-1}$ ) [31]. Such a concentration for diluate is thus a controlling factor of ED desalination in the following discussion of the ED performances.

\subsubsection{Influence of the current}

Fig. 4 depicts how the concentration of salt and organic solute in diluate and concentrate respectively vary with time, with results for acetic acid/ $\mathrm{NaCl}$ system under $2 \mathrm{~A}$ and $6 \mathrm{~A}$ as an example. Desalting the diluate $\mathrm{NaCl}$ to $0.3 \mathrm{eq} \cdot \mathrm{L}^{-1}$ under different currents means extracting a given amount of salt, or more precisely identical quantity of electrical charge, as production of current and time (I.t).

Clearly, to reach the objective (critical salt concentration in diluate), a higher current gives less time required. Meanwhile, different concentration of organic solute is achieved, with a higher current giving a lower organic solute concentration.

Table 6 further compares the organic solute transfer under different current, given the same amount of salt removed, where organic solute concentration in concentrate are calculated by Eq. (8). More precisely, three concentration values are reported, referred as the total value

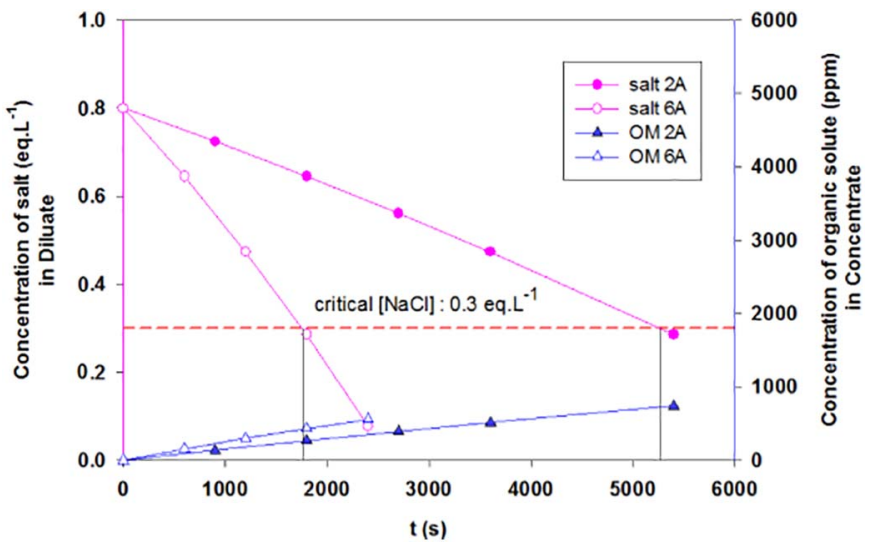

Fig. 4. Variation of the concentration of salt in diluate and concentration of organic solute in concentrate versus time: influence of the current $\mathrm{NaCl}$ /acetic acid system, $\mathrm{I}=2 \mathrm{~A}$ and $6 \mathrm{~A},[\mathrm{NaCl}]=0.8 \mathrm{eq} \cdot \mathrm{L}^{-1}$, [acetic acid $]=6000 \mathrm{ppm}$. 
Table 6

Desalination performance under two different currents $\mathrm{NaCl} /$ Acetic acid system, organic solute concentration calculated according to Eq. (8), $[\mathrm{NaCl}]=0.8 \mathrm{eq} \cdot \mathrm{L}^{-1}$, [acetic acid] $=6000 \mathrm{ppm}$.

\begin{tabular}{llllll}
\hline I (A) & Time (s) & $\begin{array}{l}\text { Electrical charge } \\
(\mathrm{C})\end{array}$ & $\begin{array}{l}C_{O M}^{\text {total }} \\
(\mathrm{ppm})\end{array}$ & $\begin{array}{l}C_{O M}{ }^{\text {diff }} \\
(\mathrm{ppm})\end{array}$ & $\begin{array}{l}C_{O M}{ }^{\text {conv }} \\
(\mathrm{ppm})\end{array}$ \\
\hline 2 & 5265 & 10,530 & 720 & 450 & 270 \\
6 & 1755 & 10,530 & 420 & 150 & 270 \\
\hline
\end{tabular}

$C_{O M}{ }^{\text {total }}$ considering both the diffusion and convection, the value owing to diffusion only $\left(C_{O M}\right.$ diff, assuming $\left.\gamma=0\right)$, and the one owing to convection only $\left(C_{O M}{ }^{\text {conv }}\right.$, assuming $\left.P_{O M}=0\right)$, respectively.

Expectedly, the fixed initial and final salt concentrations give the constant electrical charge. Regarding the total concentrations $C_{O M}$ total, the value under $2 \mathrm{~A}$ is about 2 times of that under $6 \mathrm{~A}$, showing that higher current leads to lower organic concentration. Furthermore, the value $C_{O M}{ }^{\text {diff }}$ is time dependent under these two currents, while the values $C_{O M}{ }^{\text {conv }}$ are constant, fixed by electrical charge (I.t). The fact that under the two currents less difference between the organic solute concentrations $\left(C_{O M}{ }^{\text {total }}\right)$ is found, comparing with the gap between the two values of $C_{O M}{ }^{\text {diff }}$, can be attributed to the contribution of convection, This finding confirms that in ED organic solute convection is important to be considered.

Similar finding is also observed for other systems. Specifically, the migration of acetate, as the convection for neutral solute, is also fixed by electrical charge, referred to Eq. (8).

\subsubsection{Influence of the solute}

The impact of the present organic solute nature is discussed regarding ED performance. Fig. 5 depicts how the concentration of organic solute in concentrate varies with the concentration of salt in diluate, for system of $\mathrm{NaCl}$ mixed with varying organic compounds respectively, under $2 \mathrm{~A}$. Notably, $\mathrm{X}$ and $\mathrm{Y}$ axis represents the desalination process and the simultaneous organic solute transfer with time, respectively.

Expectedly, the concentration of organic solute increases in concentrate with decreasing concentration of salt in diluate. The influence of solute nature is observed on such a concentration increase, the order of the sequence is glucose $<$ acetic acid $<$ acetate $<$ phenol, for the concentration values in ppm.

Different sequence for organic solute transfer as glucose $<$ phenol $<$ acetic acid $<$ acetate is reported (Section 4.2), for the concentration values in unit of mole. Higher $\mathrm{M}_{\mathrm{w}}$ of phenol $\left(94 \mathrm{~g} \cdot \mathrm{mol}^{-1}\right.$ ) explains the displacement of phenol in sequence, comparing with that

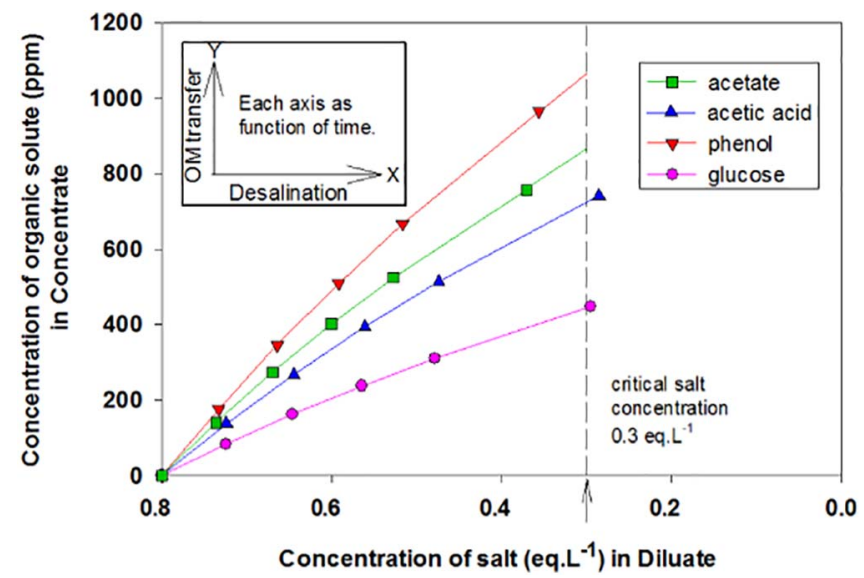

Fig. 5. Variation of the concentration of organic solute in concentrate versus the concentration of salt in diluate: influence of the solute $\mathrm{NaCl}$ /Organic solute systems, $\mathrm{I}=2 \mathrm{~A}$, [inorganic salt] $=0.8 \mathrm{eq} \cdot \mathrm{L}^{-1}$, [organic solute] $=0.1 \mathrm{~mol} \cdot \mathrm{L}^{-1}$ (acetate $5900 \mathrm{ppm}$, acetic acid 6000 ppm, phenol 9400 ppm, glucose 18,016 ppm)

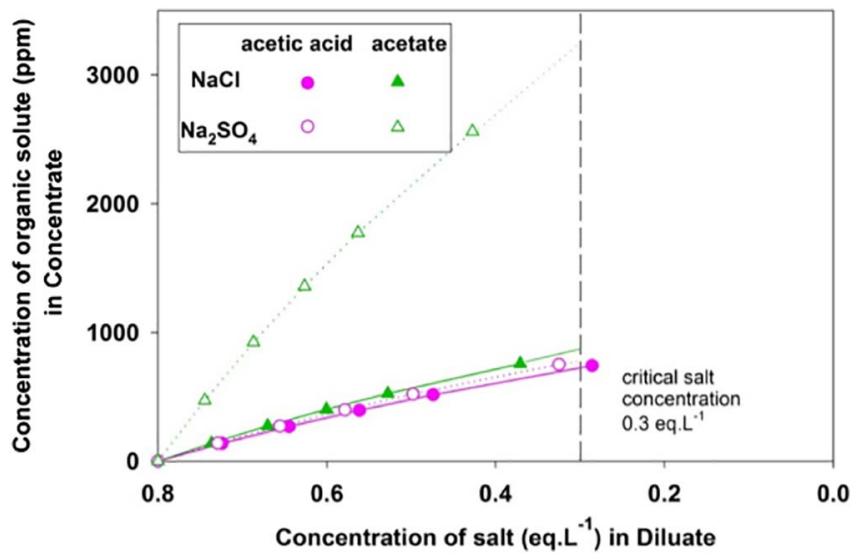

Fig. 6. Variation of the concentration of organic solute in concentrate versus the concentration of salt in diluate: influence of the salt compositions $\mathrm{NaCl}-\mathrm{Na}_{2} \mathrm{SO}_{4}$ /organic solute systems, I $=2 \mathrm{~A}$, [inorganic salt] $=0.8 \mathrm{eq} \cdot \mathrm{L}^{-1}$, [organic solute] $=0.1 \mathrm{~mol} \cdot \mathrm{L}^{-1}$ (acetate $5900 \mathrm{ppm}$, acetic acid $6000 \mathrm{ppm}$ )

of acetate $\left(59 \mathrm{~g} \cdot \mathrm{mol}^{-1}\right)$. Nevertheless, this result in Fig. 5 suggests that it is more difficult to treat phenol-contained solution than others, owing to its higher phenol transfer.

\subsubsection{Influence of the salt}

Fig. 6 illustrates the effect of salt on ED performance, comparing the transfer of acetic acid and acetate due to the present $\mathrm{NaCl}$ and $\mathrm{Na}_{2} \mathrm{SO}_{4}$, respectively.

Regardless of the solute nature of charge, the organic compound transfer with $\mathrm{Cl}^{-}$is always lower than that with $\mathrm{SO}_{4}{ }^{2-}$, under given salt concentration in diluate. Such a difference owing to the present anion on the transfer of organic compound is more significant for acetate than for acetic acid.

Table 7 further compares the impact of the salt composition on organic transfer, when the final diluate concentration reached $0.3 \mathrm{eq} \cdot \mathrm{L}^{-1}$.

Clearly, the difference of organic transfer with anion $\mathrm{SO}_{4}{ }^{2-}$ and $\mathrm{Cl}^{-}$ is shown with each compound. The same tendency for transfer of glucose, acetic acid and acetate is observed: $\mathrm{SO}_{4}{ }^{2-}>\mathrm{Cl}^{-}$. Such an impact of anion is more pronounced for acetate, acetate transfer with $\mathrm{SO}_{4}{ }^{2-}$ being higher compared to that with $\mathrm{Cl}^{-}$by a factor of 3-4. Contrarily, in the case of phenol, $\mathrm{Cl}^{-}$gives a higher transfer than that with $\mathrm{SO}_{4}{ }^{2-}$ by a factor of ca. 1.5. The reasons are already discussed in Section 4.2, thus not detailed here.

In ED process point of view, improved desalination performances are suggested by the solution composition modification. Using the reported highest transfer for system of acetate $-\mathrm{SO}_{4}{ }^{2-}$ for example, the following two approaches can be recommended to reduce the acetate transfer. One is to transform acetate, from a weak acid salt to acetic acid (its neutral form), by $\mathrm{pH}$ adjustment. Indeed, Table 7 clearly shows that the concentration for acetate, ca. 3200 ppm drastically declined to ca. $800 \mathrm{ppm}$ for acetic acid in the investigated condition. The other approach to decrease the acetate transfer depends on co-existing salt or ion species, e.g. choosing a membrane with a stronger selectivity or changing the salt composition. The latter approach is confirmed by

Table 7

Influence of the salt composition on organic solute transfer $\mathrm{NaCl}-\mathrm{Na}_{2} \mathrm{SO}_{4}$ /organic solute systems, $\mathrm{I}=2 \mathrm{~A}$, [inorganic salt] $=0.8 \mathrm{eq} \cdot \mathrm{L}^{-1}$, [organic solute] $=0.1 \mathrm{~mol} \cdot \mathrm{L}^{-1}$ (acetate $5900 \mathrm{ppm}$, acetic acid $6000 \mathrm{ppm}$, phenol 9400 ppm, glucose 18,016 ppm) organic solute concentration calculated according to Eq. (8).

\begin{tabular}{lllll}
\hline$C_{\text {OM }}{ }^{\text {total }}(\mathrm{ppm})$ & Glucose & Phenol & Acetic acid & Acetate \\
\hline $\mathrm{NaCl}$ & 448 & 1060 & 723 & 849 \\
$\mathrm{Na}_{2} \mathrm{SO}_{4}$ & 473 & 673 & 775 & 3193 \\
\hline
\end{tabular}


much lower acetate concentration with $\mathrm{SO}_{4}{ }^{2-}$ compared to $\mathrm{Cl}^{-}$, by a factor of ca. 4. Modification on salt compositions could be also effective in controlling phenol transfer considering the significant difference with $\mathrm{SO}_{4}{ }^{2-}$ and $\mathrm{Cl}^{-}$, respectively (Table 7).

To sum up, attention for a better ED performance control should concern not only process parameters (like current) but also the solution compositions (both salt and organic solutes).

\section{Conclusions}

The objective of this paper was to propose a phenomenological model in order to investigate the electrodialysis performance in desalting saline solution containing organic solute. Experiments were performed using brines of varying compositions, i.e. salt mixed with organic solute of different nature of size, hydrophilicity, charge. The mass transfer investigation for solvent and solute in electrodialysis was conducted.

Firstly, inorganic salt and water transfer was studied, and corresponding characteristic parameters ( $\alpha$ and $\beta$ ) were experimentally obtained. The presence of neutral solute didn't affect the transfer of salt and water. Competition of acetate with inorganic salt for current transfer was observed, where the total salt transfer with both contributions included is still constant and equal to those without solute.

Organic solute transfer comprised contribution of diffusion, characterized by $\left(P_{O M}\right)$, and additional transfer, characterized by $(\gamma)$ which is proportional to the current. More precisely, the additional transfer of organic compound is convection for the neutral one owing to electroosmosis, migration for charged one. Acetic acid convection is less important than acetate migration.

Finally, a phenomenological model involving 4 characteristic coefficients was proposed, on the basis of the transfer of salt $(\alpha)$ and water $(\beta)$ as well as organic solute, including the diffusion $\left(P_{O M}\right)$ without current and the additional one $(\gamma)$ with current. With this model, it is possible to calculate the variation of both the solution volume and concentration for salt and organic solute respectively, in either compartment, as a function of their initial values and of the current. The formalism of model is valid for any system. However, the parameters (for transfer of salt $(\alpha)$, water $(\beta)$ and organic solute $\left(P_{O M}, \gamma\right)$ ) depend on the membrane properties and they have to be determined experimentally. Application of the model in up-scaled system is highly possible given similar operation of electrodialysis in a quasi-steady conditions, such as comparable potential drop per cell, hydrodynamics and mass transfer in the channel, etc. [32,33].

ED performance was then evaluated in a case study regarding the effect of the current and solution compositions. For a fixed salt quantity removed, a lower current gives a higher organic solute transfer. This result can be mainly attributed to the contribution of the solute diffusion, which depends on time. Additional transfer, also important in ED process, is controlled by the electrical charge. Finally, the effect of the solution compositions with a regard to both the organic solute and salt nature was discussed. Sulfate resulted higher solute transfer compared to chloride for glucose and acetic acid due to solute dehydration effect. Same trend but more important influence was observed for acetate due to anion selectivity. The reversed trend was observed for phenol. This result suggests pretreatment to further improve the ED performance such as salt composition and solution $\mathrm{pH}$ control.

\section{Nomenclature}

\section{List of symbols}

$C_{O M, D}{ }^{0}, C_{O M, C}{ }^{0}$ intial solute concentration in diluate and concentrate $\left(\mathrm{mol} \cdot \mathrm{m}^{-3}\right)$

$\Delta C_{O M} \quad$ solute concentration gradient $\left(\mathrm{mol} \cdot \mathrm{m}^{-3}\right)$

I current intensity (A)

$j_{s} \quad$ salt flux $\left(\mathrm{eq} \cdot \mathrm{m}^{-2} \cdot \mathrm{s}^{-1}\right)$

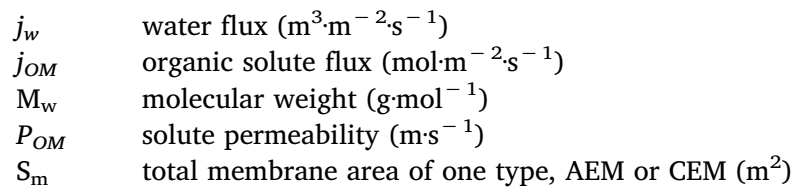

Greek symbols

$\alpha \quad$ current coefficient (eq $\left.\cdot \mathrm{m}^{-2} \cdot \mathrm{s}^{-1} \cdot \mathrm{A}^{-1}\right)$

$\beta \quad$ electroosmotic coefficient $\left(\mathrm{m}^{3} \cdot \mathrm{m}^{-2} \cdot \mathrm{s}^{-1} \cdot \mathrm{A}^{-1}\right)$

$\gamma \quad$ additional transfer coefficient $\left(\mathrm{m} \cdot \mathrm{s}^{-1} \cdot \mathrm{A}^{-1}\right)$

\section{Superscripts \& subscripts}

additional additional transfer

conv convection

diff diffusion

eo electroosmosis

mig migration

\section{Acknowledgements}

China Scholarship Council (CSC), Ministry of Education, P. R. China is acknowledged for the scholarship provided to Le Han.

\section{References}

[1] O. Lefebvre, R. Moletta, Treatment of organic pollution in industrial saline wastewater: a literature review, Water Res. 40 (2006) 3671-3682.

[2] H. Strathmann, Ion-exchange Membrane Separation Processes, Elsevier Science, Stuttgart, 2004.

[3] H. Strathmann, Electrodialysis, a mature technology with a multitude of new applications, Desalination 264 (2010) 268-288.

[4] C. Huang, T. Xu, Y. Zhang, Y. Xue, G. Chen, Application of electrodialysis to the production of organic acids: state-of-the-art and recent developments, J. Membr. Sci. 288 (2007) 1-12.

[5] C. Abels, F. Carstensen, M. Wessling, Membrane processes in biorefinery applications, J. Membr. Sci. 444 (2013) 285-317.

[6] F.J. Borges, H. Roux-de Balmann, R. Guardani, Investigation of the mass transfer processes during the desalination of water containing phenol and sodium chloride by electrodialysis, J. Membr. Sci. 325 (2008) 130-138.

[7] Y. Zhang, K. Ghyselbrecht, B. Meesschaert, L. Pinoy, B. Van der Bruggen, Electrodialysis on RO concentrate to improve water recovery in wastewater reclamation, J. Membr. Sci. 378 (2011) 101-110.

[8] B.E. Logan, M. Elimelech, Membrane-based processes for sustainable power generation using water, Nature 488 (2012) 313-319.

[9] M. Vanoppen, A.F.A.M. Bakelants, D. Gaublomme, K.V.K.M. Schoutteten, J. Vanden Bussche, L. Vanhaecke, et al., Properties governing the transport of trace organic contaminants through ion-exchange membranes, Environ. Sci. Technol. 49 (2015) $489-497$.

[10] Y. Zhang, B. Van der Bruggen, L. Pinoy, B. Meesschaert, Separation of nutrient ions and organic compounds from salts in RO concentrates by standard and monovalent selective ion-exchange membranes used in electrodialysis, J. Membr. Sci. 332 (2009) 104-112.

[11] Y. Zhang, P. Luc, B. Meesschaert, B. Van der Bruggen, Separation of small organic ions from salts by ion-exchange membrane in electrodialysis, AICHE J. 57 (2011) 2070-2078.

[12] P. Dydo, The mechanism of boric acid transport during an electrodialytic desalination process, J. Membr. Sci. 407-408 (2012) 202-210.

[13] L.J. Banasiak, A.I. Schäfer, Removal of boron, fluoride and nitrate by electrodialysis in the presence of organic matter, J. Membr. Sci. 334 (2009) 101-109.

[14] L. Han, S. Galier, H. Roux-de Balmann, Transfer of neutral organic solutes during desalination by electrodialysis: influence of the salt composition, J. Membr. Sci. 511 (2016) 207-218.

[15] S. Galier, H. Roux-de Balmann, Demineralization of glucose solutions by electrodialysis: influence of the ionic composition on the mass transfer and process performances, Can. J. Chem. Eng. 93 (2015) 378-385.

[16] A. Fuoco, S. Galier, H. Roux-de Balmann, G. De Luca, Correlation between macroscopic sugar transfer and nanoscale interactions in cation exchange membranes, J. Membr. Sci. 493 (2015) 311-320.

[17] V. Boy, H. Roux-de Balmann, S. Galier, Relationship between volumetric properties and mass transfer through NF membrane for saccharide/electrolyte systems, J. Membr. Sci. 390-391 (2012) 254-262.

[18] K. Bawornruttanaboonya, S. Devahastin, T. Yoovidhya, N. Chindapan, Mathematical modeling of transport phenomena and quality changes of fish sauce undergoing electrodialysis desalination, J. Food Eng. 159 (2015) 76-85.

[19] M. Bailly, H. Roux-de Balmann, P. Aimar, F. Lutin, M. Cheryan, Production 
processes of fermented organic acids targeted around membrane operations: design of the concentration step by conventional electrodialysis, J. Membr. Sci. (2001) 129-142.

[20] M. Fidaleo, M. Moresi, Electrodialytic desalting of model concentrated $\mathrm{NaCl}$ brines as such or enriched with a non-electrolyte osmotic component, J. Membr. Sci. 367 (2011) 220-232.

[21] C. Jiang, Y. Wang, Z. Zhang, T. Xu, Electrodialysis of concentrated brine from RO plant to produce coarse salt and freshwater, J. Membr. Sci. 450 (2014) 323-330.

[22] L. Han, S. Galier, H. Roux-de Balmann, Ion hydration number and electro-osmosis during electrodialysis of mixed salt solution, Desalination 373 (2015) 38-46.

[23] Y. Gong, L.M. Dai, X.L. Wang, L.X. Yu, Effects of transport properties of ion-exchange membranes on desalination of 1,3-propanediol fermentation broth by electrodialysis, Desalination 191 (2006) 193-199.

[24] T.F. Fuller, J. Newman, Experimental determination of the transport number of water in nafion 117 membrane, J. Electrochem. Soc. 139 (1992) 1332-1337.

[25] B.D. Bath, H.S. White, E.R. Scott, Electrically facilitated molecular transport. Analysis of the relative contributions of diffusion, migration, and electroosmosis to solute transport in an ion-exchange membrane, Anal. Chem. 72 (2000) 433-442.

[26] L.Q. Gu, S. Cheley, H. Bayley, Electroosmotic enhancement of the binding of a neutral molecule to a transmembrane pore, PNAS 100 (2003) 15498-15503.
[27] A. Leo, C. Hansch, D. Elkins, Partition coefficients and their uses, Chem. Rev, 71 (1971) 525.

[28] S. Galier, J. Savignac, H. Roux-de Balmann, Influence of the ionic composition on the diffusion mass transfer of saccharides through cation-exchange membrane, Sep. Purif. Technol. 109 (2013) 1-8.

[29] F. Ludzack, D. Noran, Tolerance of high salinities by conventional wastewater treatment processes, J. Water Pollut. Control Fed. 37 (1965) 1404-1416.

[30] R. Maciel, G.L. Sant'Anna, M. Dezotti, Phenol removal from high salinity effluents using Fenton's reagent and photo-Fenton reactions, Chemosphere 57 (2004) 711-719.

[31] E. Singlande, H. Roux-de Balmann, X. Lefevbre, M. Sperandio, Improvement of the treatment of salted liquid waste by integrated electrodialysis upstream biological treatment, Desalination 199 (2006) 64-66.

[32] E.V. Laktionov, N.D. Pismenskaya, V.V. Nikonenko, V.I. Zabolotsky, Method of electrodialysis stack testing with the feed solution concentration regulation, Desalination 151 (2002) 101-116.

[33] V.V. Nikonenko, N.D. Pismenskaya, A.G. Istoshin, V.I. Zabolotsky, A.A. Shudrenko, Description of mass transfer characteristics of ED and EDI apparatuses by using the similarity theory and compartmentation method, Chem. Eng. Process. Process Intensif. 47 (2008) 1118-1127. 